\title{
Modernidad, religión y discurso político en América Latina ${ }^{1}$
}

\section{Modernity, religion and political discourse in Latin America}

Recibido: 06 de julio de 2015 - Revisado: 27 de julio de 2015 - Aceptado: 03 de agosto de 2015

Iván Garzón Vallejo ${ }^{2}$

Cristian Rojas González ${ }^{3}$

\section{Resumen}

Las intervenciones de siete políticos latinoamericanos en los debates acerca del matrimonio de parejas del mismo sexo y el aborto en el sistema político y en la esfera pública política, permiten analizar la naturaleza y el potencial alcance de los argumentos más relevantes en su discurso público. Los casos estudiados son representativos de las tensiones entre religión y modernidad política en América Latina: por un lado hay un uso instrumental del lenguaje religioso, y por otro hay una traducción de valores morales y creencias religiosas a un lenguaje secular que pueda ser entendido y eventualmente compartido por todos los ciudadanos.

\section{Palabras clave}

Laicidad, América Latina, discurso político, democracia deliberativa, matrimonio homosexual, aborto.

\begin{abstract}
Interventions of seven Latin American politicians in debates about marriage of same-sex couples and abortion in the political system and the political public sphere, make it possible to analyze the nature and potential scope of the most important arguments in public discourse. The cases studied here are representative of the tensions between religion and political modernity in Latin America: on the one hand there is an instrumental use of religious language, and on the other hand there is a translation of moral values and religious beliefs into a secular language that can be understood and perchance shared by all citizens.
\end{abstract}

\section{Keywords}

Secularism, Latin America, political discourse, deliberative democracy, samesex marriage, abortion.

\footnotetext{
${ }^{1}$ Este artículo es un producto del proyecto de investigación "Religión y moral en el liberalismo contemporáneo", financiado por la Universidad de La Sabana, Bogotá, Colombia.

${ }^{2}$ Doctor en Ciencias Políticas de la Pontificia Universidad Católica Argentina, Buenos Aires, Argentina. Abogado de la Universidad Pontificia Bolivariana, Medellín, Colombia Allí mismo realizó estudios de Filosofía. Actualmente es profesor asociado de la Universidad de La Sabana, Bogotá, Colombia; y director del Programa de Ciencias Políticas de la misma institución.

Correo electrónico:

ivan.garzon1@unisabana.edu.co

${ }^{3}$ Magíster en Filosofía Aplicada de

la Universidad de los Andes, Santiago de Chile, Chile. Politólogo de la Universidad del Rosario, Bogotá, Colombia. En la actualidad es profesor asistente de la Universidad de La Sabana, Bogotá, Colombia.

Correo electrónico:

cristian.rojas@unisabana.edu.co

Para citar este artículo use: Garzón Vallejo, I. \& Rojas, C. (2016). Modernidad, religión y discurso político en América Latina. Revista Civilizar Ciencias Sociales y Humanas, 16(30), 89-104.
} 
It's time that we join a serious debate about how to reconcile faith with our modern, pluralistic democracy

Barack Obama

\section{Introducción}

Día a día, los políticos intervienen en muchos ámbitos de la vida social y cultural: reuniones, encuentros, mítines, convenciones, juntas, comunicaciones virtuales. Sin embargo, cuando intervienen en el sistema político y en la esfera pública política es posible diseccionar sus discursos para efectos de un análisis teórico. Como los receptores potenciales del discurso en estos ámbitos son todos los ciudadanos, es deseable que los políticos hagan un ejercicio de razonamiento público, es decir, que contribuyan a ilustrar la discusión formulando argumentos que puedan ser comprendidos y aceptados por cualquiera, y no solo por sus partidarios.

Esta pauta de comunicación, no obstante, no se aplica cuando el ejercicio de comunicación política se realiza en ámbitos de la sociedad civil (partidos, gremios, asociaciones, organizaciones, iglesias, universidades, fundaciones), pues en estos los participantes de las deliberaciones suelen compartir los mismos presupuestos epistémicos y axiológicos. Luego, allí el político no se dirige a un auditorio universal sino a uno específico.

El diagrama 1 ilustra los modos de comunicación y los actores que intervienen en los tres niveles de los foros de la comunicación política: el sistema político, la esfera pública política y la sociedad civil.

\section{Diagrama 1 \\ Foros de la comunicación política}

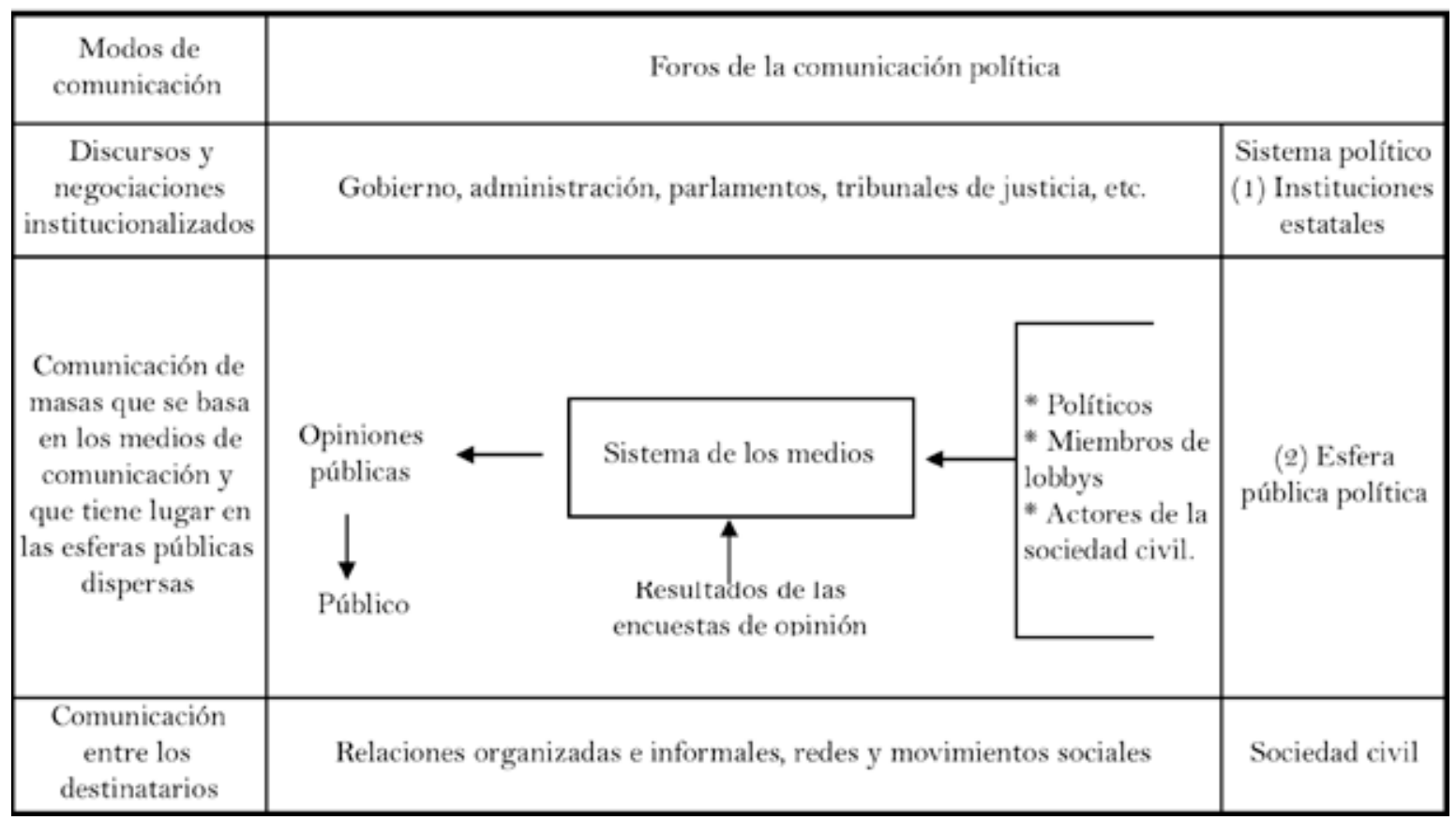

Fuente: Habermas, 2009a, p. 160.

En América Latina los políticos suelen rehuir plantear abiertamente y convertir en tema de campaña su posición acerca de asuntos morales controversiales, como son, por ejemplo, el matrimonio de parejas del mismo sexo y el aborto. Sin embargo, en los últimos años se ha 
hecho inevitable que se pronuncien al respecto, toda vez que los dos asuntos han adquirido notoriedad en la agenda pública: entre el año 2010 y 2015 se radicaron 22 proyectos de ley sobre estas materias en los órganos legislativos de la región -once sobre matrimonio de parejas del mismo sexo $^{1}$ y once sobre aborto $^{2}-$, lo que a su vez suscitó un debate público en los medios de comunicación. Allí han tenido que comparecer algunos políticos para presentar su postura y someterla al escrutinio ciudadano.

Pero no solo los políticos adquirieron protagonismo en la discusión pública de estos temas. En los últimos años, algunos líderes religiosos - católicos y de otras confesiones cristianas- han desempeñado un papel relevante en tales debates. Los nombres de Juan Luis Cipriani y Humberto Lay (Perú), Julio Terrazas (Bolivia) y Fernando Lugo (Paraguay) son muestras representativas del peso político de los actores religiosos en el continente (Bohoslavski, 2013, p. 39).

Los temas públicos controversiales tienen el potencial de exponer una gran variedad de razones morales, religiosas, filosóficas, jurídicas y políticas, pues se trata de asuntos sobre los cuales los ciudadanos ilustrados reclaman un elenco de argumentos para formar su opinión y voluntad políticas. También porque las discusiones sobre estos son dialécticas y usualmente apasionadas, y porque se trata de cuestiones divisivas de las sociedades modernas, que tienen la capacidad de separar a la gente en bandos a favor o en contra.

El estudio Religion in Latin America. Widespread change in a historically catholic region evidencia que en América Latina existe una tendencia contraria a la legalización del matrimonio de parejas del mismo sexo y del aborto, en porcentajes que llegan hasta el 83 $\%$ (en Honduras) en el caso de aquel, y del 95 $\%$ (en Paraguay) en el caso de este. Aunque en países como Uruguay (62\%), Argentina (52 $\%$ ), México (49\%) y Chile (46\%) la opinión favorable al matrimonio de parejas del mismo sexo supera a la desfavorable. Y en el caso del aborto, hay países como Uruguay donde el apoyo es mayoritario (54 \%) y Chile donde casi lo es: $47 \%$ contra $49 \%$ (Pew Research Center, 2014, pp. 21, 69, 73).

Cuando estas cuestiones se plantean en el debate público es frecuente que sean formuladas con posturas carentes de matices, cargadas de lugares comunes y sin el potencial de alcanzar acuerdos o compromisos (Garzón Vallejo, 2014, pp. 101-107). En este marco, este trabajo recoge la intervención en el sistema político o en la esfera pública política de siete políticos latinoamericanos: Marco Feliciano (Brasil), Nelson Zavala (Ecuador), Roberto Gerlein (Colombia) y Liliana Negre de Alonso (Argentina) en el debate sobre el matrimonio de parejas del mismo sexo; Tabaré Vásquez (Uruguay), Sebastián Piñera (Chile) y Rosario Murillo (Nicaragua) en el debate sobre el aborto, a fin de analizar cómo fueron presentados los argumentos públicos inspirados en creencias religiosas sobre ambos temas.

El artículo se estructura alrededor de estas dos preguntas: a) ¿en estas discusiones se presentaron preponderantemente argumentos morales, filosóficos y religiosos -las doctrinas comprensivas según Rawls- o argumentos jurídicos y políticos?, y b) ¿las creencias religiosas se expresaron en forma literal y normativa, o fueron traducidas a razones políticas seculares de modo que puedan ser compartidas también por quienes no tienen la cosmovisión del emisor del mensaje?

La escogencia de los discursos políticos obedeció a dos criterios de selección: a) que se tratara de casos en los cuales se expusieran explícitamente argumentos religiosos, morales, políticos y jurídicos; y b) que estos fueran presentados en el sistema político (Congreso o Asamblea General) o en la esfera pública política (medios de comunicación escritos preferentemente). La utilización de ambos criterios 
arrojó como resultado un listado de siete políticos de diferentes naciones que, por su número, podría considerarse una muestra relativamente representativa de la región, pero no pretende ser exhaustiva y desconocemos si en alguna intervención posterior de menor audiencia el referido político matizó o modificó su postura. Aunque muchos otros políticos se refirieron a estos temas y sus discursos o declaraciones pudieron ser muy polémicos, no cumplían los dos requisitos que definimos para el análisis.

Para el estudio de los siete casos se recurrirá a una metodología inductiva -en la recolección de los extractos relevantes de los discursos- y el análisis se hará siguiendo las pautas del macromolde hermenéutico, en específico, tomando como criterio orientador tres de sus principios: que la interpretación tiene como objetivo una comprensión profunda de los fenómenos políticos; que un discurso político es un texto susceptible de ser interpretado; y que la identidad de los actores políticos se construye socialmente (Losada \& Casas, 2008, pp. 52-53).

Con ello pretendemos mostrar básicamente: a) que la idea de la traducción como una forma de razonamiento público que justifica y formula el discurso político de modo que pueda ser comprendido por un mayor número de ciudadanos es utilizada por algunos políticos con independencia del tema que se aborde; y b) en boca de los políticos estudiados, el lenguaje religioso suele reflejar una lectura literal, normativa e instrumental de la Biblia como texto sagrado que podría estar dirigido - de forma conscienteúnicamente hacia sus seguidores. No obstante, en el debate público, ello produjo el efecto de radicalizar las posiciones antagónicas.

Ambos aspectos sugieren que la reconciliación entre religión y modernidad política aún es una asignatura pendiente en América Latina. Pero los discursos políticos traducidos permiten afirmar que estamos lejos de las diatribas laicistas según las cuales en América Latina no existe una real separación entre las iglesias y el
Estado; y de las tradicionalistas, según las cuales los argumentos religiosos no pueden expresarse públicamente porque son sofocados por el entorno secularista.

\section{El debate sobre el matrimonio de parejas del mismo sexo: Marco Feliciano, Nelson Zavala, Roberto Gerlein y Liliana Negre de Alonso}

La elección en 2013 del diputado Marco Feliciano como presidente de la Comisión de Derechos Humanos y Minorías en la Cámara de Diputados suscitó revuelo mediático en Brasil, pues eran conocidas sus posturas en contra del matrimonio de parejas del mismo sexo. En una entrevista publicada por la influyente revista Veja, el diputado tuvo la oportunidad de ampliar su postura al respecto y señaló: "la união homossexual não é normal. O reto não foi feito para ser penetrado. Não haveria condição de dar sequência à nossa raça. Agora, o que se faz dentro de quatro paredes não me diz respeito". En la misma entrevista manifestó que "Os gays destroem qualquer pessoa que se levante contra eles", y que "O casamento gay fere os direitos da igreja"3 (Feliciano, 2013, pp. 17-21).

En el mismo sentido, Nelson Zavala, pastor de una comunidad cristiana evangélica y candidato del Partido Roldosista Ecuatoriano para las elecciones presidenciales de 2012, afirmó en un medio de comunicación que

[...] la tolerancia no puede existir para los actos de inmoralidad. Yo consideraré toda mi vida conforme a mis principios que son bíblicos que la homosexualidad es un acto de inmoralidad. Yo al homosexual siempre lo he aceptado, siempre lo he amado, y lo he ayudado [...] Como presidente tendremos que realizar una normativa para que el homosexual respete la verdadera familia, que es la familia heterosexual. No podemos permitir marchas de orgullo gay, donde hay actitudes degenerativas, eso no puede ser [...] Ellos deben ser tolerantes (Zavala, 23 de noviembre de 2012). 
En la discusión que tuvo lugar en Colombia sobre el matrimonio de parejas del mismo sexo tuvo amplia resonancia mediática la intervención del senador Roberto Gerlein durante la sesión de la Comisión Primera del Senado de la República en la que expresó: "El catre compartido entre dos varones: ¡Qué horror Dios mío! [...] ese es un sexo sucio, asqueroso, un sexo que merece repudio, un sexo excremental". Y ahondando en las razones de su postura, el senador del Partido Conservador añadió:

Por naturaleza, son repudiados -los excesos de las uniones homosexuales- por esa misma naturaleza $[\ldots]$ A ustedes no les gusta la $B i$ blia pero a mí me gusta [...] le voy a citar el Génesis... la voz del Padre, la voz de Dios: Creced y multiplicaos, poblad la tierra (Gerlein, 2012).

En la Argentina, por el contrario, la discusión legislativa sobre el mismo tema tuvo una expositora que no exhibió un discurso destinado solo a quienes pensaban como ella $\mathrm{y}$, por el contrario, en el mismo había una integración entre una perspectiva secular $\mathrm{y}$ religiosa cargada de matices. Así, al reconocer que el proyecto de ley en discusión era una legislación para un Estado laico, la senadora Liliana Negre de Alonso advertía que ello no significaba borrar las convicciones que cada uno de los ponentes tuvo en el momento de hacer públicas sus posiciones (Negre de Alonso, 2010, p. 18). En este sentido, la senadora del Partido Justicialista ponía de presente la convergencia entre las tradiciones religiosas y las tradiciones seculares al señalar:

Si nosotros nos queremos olvidar absolutamente de la religión o mirar desde el positivismo las limitaciones y las regulaciones, veremos que en casi todos los códigos penales del mundo están penados el hurto, el homicidio, la violación, los abusos sexuales. De hecho, si vamos al origen de la religión judeocristiana, los Diez Mandamientos no hacen ni más ni menos que penar: no robarás, no cometerás adulterio, no violarás, etcétera. $\mathrm{O}$ sea que por más que que- ramos separarlos llega un momento en que por nuestra misma historia y nuestra misma tradición tienen un argumento en común (Negre de Alonso, 2010, p. 19).

También resulta significativa en el discurso de la senadora la defensa de la razonabilidad de los argumentos como parámetro de la discusión pública, y su convicción de traducir las creencias religiosas a un lenguaje secular:

El pasaporte al debate es la razonabilidad intrínseca de los argumentos. No en nombre del liberalismo podemos destruir las propias libertades sino que, desde las convicciones de cada uno, en el ámbito público debemos verter nuestros argumentos inteligibles al hombre común para que los comprenda y para que la comunidad en su conjunto pueda caminar hacia la construcción del bien común (Negre de Alonso, 2010, p. 19).

Los argumentos formulados por Feliciano, Zavala y Gerlein en el debate público sobre el matrimonio de parejas del mismo sexo hacen notar el recurso a un lenguaje religioso sin la pretensión de que llegue a ser compartido por quienes no tienen la misma base epistémica y axiológica. Por ello, no hay un desarrollo acerca del significado o pertinencia de las referencias bíblicas, sino que se invocan como argumentos de autoridad. No se formulan matices ni explicaciones para quienes no consideren la Biblia un texto normativo o sagrado, ni tampoco se buscan puntos de encuentro con una perspectiva secular.

En el caso de Negre de Alonso se revela el ejercicio de la traducción de creencias morales y religiosas a argumentos seculares de carácter cultural, jurídico y político que puedan ser compartidos por todos los ciudadanos, poniendo de relieve los aspectos sobre los cuales existen convergencias entre creyentes y no creyentes: el valor de la razonabilidad, el contexto laico y liberal, la existencia de convicciones en todos los senadores y coincidencias religiosas y seculares en aquello que ambas rechazan. 
El uso de estas formas lingüísticas y discursivas designan dos paradojas: en el caso de los argumentos religiosos y bíblicos no surten el efecto de hacer más solemne la discusión o generar mayor respeto hacia la fuente de los mismos, sino que, por el contrario, contribuyen a banalizarla y hasta a ridiculizarla, pues las referencias a los mismos en medios de comunicación y redes sociales suelen ser irónicas y sarcásticas. Y en el caso de la traducción, la paradoja es que la postura contraria al reconocimiento del matrimonio de parejas del mismo sexo fue derrotada por 27 votos contra 33. Luego, una buena traducción no parece ser el único requisito de persuasión en el discurso político. Al menos, no lo fue aquella vez en el Senado argentino.

\section{¿Es legítimo que un político presente argumentos morales y religiosos en el discurso público?}

Más allá de que el recurso a argumentos bíblicos en la discusión pública pueda ser contraproducente y evidenciar tantas falencias desde una perspectiva secular moderna, debemos preguntarnos si es legítimo que un político invoque argumentos religiosos en su discurso. Pero no solo por una cuestión de pertinencia o validez democrática, sino por una cuestión de necesidad. Y es que como se verá, algunos teóricos políticos han reconocido que existen experiencias de hondo contenido o significado que no se pueden traducir, y ante las cuales el lenguaje religioso aparece con la suficiente elocuencia y persuasión para expresarlas. Los conceptos del perdón, misericordia, solidaridad, misterio, caridad, salvación, don, gratuidad, sacrificio, sufrimiento y compasión tienen una connotación eminentemente religiosa y con dificultad podrían ser expresados de otro modo sin perder parcialmente su significado (Garzón Vallejo, 2014, pp. 270-271).

En el discurso político, el lenguaje religioso hace posible expresar experiencias que no pueden comunicarse de otra manera, que se sustraen a la capacidad de expresión del lenguaje secular (Habermas, 1990, pp. 62-63), que son intraducibles. Pero también permite transmitir con elocuencia metáforas que pueden tener un mayor efecto persuasivo o conllevar una descripción más fidedigna de lo que se quiere comunicar.

Este fue el caso de Abraham Lincoln (2005), quien en su célebre discurso de la casa dividida utilizó una metáfora bíblica para llamar la atención de los estadounidenses sobre los efectos civiles de la esclavitud. Su recurso público al lenguaje religioso es paradigmático, y un teórico liberal como John Rawls, defensor de la traducción o estipulación como forma de razonamiento público lo absuelve de cualquier violación o desconocimiento de la razón pública en el caso del Día de Ayuno Nacional (1861), y las dos proclamaciones de Día de Acción de Gracias (1863 y 1864) que aquel convocara (Rawls, 2006, p. 240). El caso de Lincoln pone de relieve la fuerza descriptiva, imaginativa y persuasiva del lenguaje religioso formulado en metáforas, analogías y alusiones directas a un texto sagrado para motivar la consecución de un objetivo político (Garzón, 2014, p. 272).

Reconociendo, por supuesto, la abismal diferencia entre el contexto norteamericano del siglo XIX y el contexto latinoamericano del siglo XXI $-\mathrm{y}$ sin pretender darle a aquel un carácter normativo-, $i$ se pueden comparar las referencias al matrimonio de parejas del mismo sexo de los políticos latinoamericanos citados con las referencias bíblicas de Lincoln? ¿Se puede establecer una analogía entre la mención al Génesis de Gerlein o la inmoralidad intrínseca del matrimonio entre parejas del mismo sexo fundada en la Biblia de Zavala y la metáfora de la "casa dividida" del presidente estadounidense como crítica a la esclavitud? ${ }^{4}$.

Creemos que no. Porque en el caso de Lincoln las referencias bíblicas tienen el propósito de situar la discusión pública en un terreno común que trascienda los argumentos partidis- 
tas. De allí que el mensaje era precisamente una convocatoria a la unidad de los bandos enfrentados. Entre tanto, en el caso de Gerlein y Zavala las referencias bíblicas parecen dirigirse únicamente a sus seguidores o copartidarios $\mathrm{y}$, dado que el tono en el que fueron formuladas fue percibido como arrogante y desafiante, contribuyeron a radicalizar las posiciones y no tendieron puentes con la postura antagónica.

Además de sus alcances y propósitos, otro aspecto problemático del uso del lenguaje religioso en los debates democráticos tiene que ver con la sospecha -fundada- como en el caso de Zavala, que anuncia una normativa destinada a prohibir manifestaciones públicas de homosexualidad -o infundada- en aquellos debates en los que se presume que quien tiene convicciones religiosas es un nostálgico de la confesionalidad estatal de que este pone en cuestión el carácter secular de las instituciones públicas.

El lenguaje oficial de las instituciones públicas debe tener una justificación secular y racional. Por ello, una ley del Parlamento o una sentencia judicial no podrían justificarse con cláusulas como: "Dado que la Biblia nos enseña que... debemos obrar de este modo" (Taylor, 2011, p. 54). Pero si es inválido asumir como oficial una posición religiosa, sería igualmente impropia una cláusula normativa en estos términos: "Como Marx ha mostrado que la religión es el opio del pueblo...", o "Como Kant ha demostrado que lo único bueno sin restricción es la buena voluntad..." (p. 54). El motivo para excluir dichas cláusulas se basa en la creencia moderna según la cual solo una justificación secular y racional garantiza un marco normativo común a todos los ciudadanos.

Por consiguiente, el Estado no puede ser cristiano, ni musulmán, ni judío, pero, por la misma razón, tampoco debe ser marxista, kantiano, libertario, ni utilitarista (Taylor, 2011, pp. 53-54). La secularidad del lenguaje oficial del Estado y las instituciones públicas se convierte en garantía de que sus órdenes y mandatos serán validados por todos los ciudadanos.

Luego, el lenguaje religioso en cuanto tal no es ilegítimo en el debate público. Pero no debe poner en riesgo los fundamentos normativos seculares de las instituciones públicas pretendiendo reemplazar tales fundamentos - como en el caso de Zavala- y, cuando es utilizado haciendo una lectura literal de un texto sagrado y de forma desafiante hacia quienes no comparten su carácter normativo -como en el caso de Feliciano y Gerlein-, puede traer como consecuencia el afianzamiento del dogmatismo ideológico y dificultar la posibilidad de alcanzar acuerdos y compromisos con las posturas antagónicas.

Sin embargo, cuando se emplea en forma inspiradora, metafórica y con el propósito de tocar fibras en los ciudadanos que las razones políticas o constitucionales no son capaces de tocar, el lenguaje religioso tiene una carga de significado moral y existencial insoslayable. Así lo ponen de presente algunos filósofos contemporáneos. Jürgen Habermas (2002, pp. $35,118)$ por ejemplo, critica los alcances de las prácticas eugenésicas refiriéndose a estas con las metáforas de "jugar a Dios" o convertirse en "compañeros de juego de la evolución", y Jacques Derrida (2006, pp. 7-39) advierte que el perdón solo tiene sentido como perdón de lo imperdonable, una experiencia ininteligible por fuera de la tradición abrahámica.

En este sentido, las experiencias históricas son abundantes. Un caso significativo se observa en el proceso de reconciliación que vivió Sudáfrica tras el apartheid, y que habría sido impensable sin el uso de referencias con raíz religiosa expresadas principalmente por el arzobispo anglicano Desmond Tutu (Van Antwerpen, 2008, p. 2). Situaciones similares se han vivido en América Latina en etapas de posconflicto, como se constata en el discurso del entonces presidente de El Salvador, Mauricio Funes, con motivo del XVIII aniversario de la firma de los acuerdos de paz que pusieron fin a la guerra 
civil y en el cual pidió perdón a las víctimas en nombre del Estado. En esa oportunidad Funes terminó su alocución pidiendo "Que Dios bendiga a El Salvador" y recordó a Óscar Arnulfo Romero como "obispo mártir y guía espiritual de la nación" (Funes, 2010), cuyo testimonio y enseñanza acompaña el camino de reconciliación de los salvadoreños.

El perdón de lo imperdonable, la reconciliación de la nación y la esperanza colectiva en momentos de crisis o tragedias (Marshall, 2002, p. 12) son algunas situaciones en las cuales el lenguaje secular exhibe serias limitaciones para ofrecer ilusión colectiva y esperanza a los ciudadanos. Por eso el lenguaje religioso puede hacer un aporte cognitivo, simbólico y normativo que el Estado constitucional debe reconocer como una contribución a la deliberación democrática (Habermas, 2006, p. 10).

\section{El debate sobre el aborto: Rosario Murillo, Tabaré Vásquez y Sebastián Piñera}

En 2011, durante la contienda electoral en Nicaragua por la presidencia de la República, el país vivió la polémica alrededor del caso de una menor de doce años que, como consecuencia de una violación quedó en embarazo con aparente riesgo para su salud. En 2007, en el Gobierno de Daniel Ortega y por iniciativa suya, una ley penalizó el aborto en todos los casos. Por ello, en 2011 no se autorizó el aborto para la menor, lo que suscitó reclamos de algunos sectores del país y de organizaciones internacionales. Finalmente la niña dio a luz sin complicaciones serias de salud, por lo cual la campaña de Ortega aprovechó esta situación para respaldar sus políticas antiabortistas. Para ello invocó un discurso político que contenía referencias religiosas explícitas.

Rosario Murillo, esposa de Ortega, lideró esta campaña y se refirió al caso de la niña como "un milagro, un signo de Dios" y diciendo que "Dios nos sigue bendiciendo con prodigios, milagros en esta Nicaragua llena de fe" (Salinas, 2 de noviembre de 2011). Así mismo, la señora Murillo justificó la legislación nicaragüense sobre el aborto apelando a la mayoría creyente del país: "Hemos trabajado de acuerdo con las creencias y costumbres de la cultura mayoritaria de Nicaragua, en defensa de la vida" (Salinas, 2 de noviembre de 2011).

En la página oficial de la Presidencia de Nicaragua puede hallarse un importante número de discursos y artículos que ponen en evidencia el constante uso del lenguaje religioso por parte de Daniel Ortega y Rosario Murillo. El mandatario se ha referido a la "esencia cristiana" de la revolución sandinista, y su discurso con motivo del 117 aniversario del natalicio de Augusto César Sandino, líder de la rebelión contra la invasión norteamericana terminaba con la exhortación a "no perder la fe, no perder la esperanza ¡la fe mueve montañas! ¡Cristo mueve montañas! Y este pueblo es cristiano, socialista y solidario. ¡Que viva Sandino!”.

Las expresiones de Ortega recuerdan aquellas del expresidente venezolano Hugo Chávez: "Cristo fue uno de los más grandes socialistas, el primero de nuestra era y Judas el más grande capitalista" (Rojas, 2013, p. 159). Ambos discursos adolecen de una formulación y justificación que pueda ser aceptada por quienes no veneran religiosamente la revolución socialista o por quienes no asumen una interpretación marxista de los evangelios al modo de la teología de la liberación.

Al sur del continente, el presidente uruguayo Tabaré Vásquez no era reconocido como un creyente, ni había hecho alusiones religiosas en la esfera pública política que permitieran afirmar que en sus manifestaciones de oposición al aborto estaba haciendo una traducción de sus convicciones religiosas. Sin embargo, los argumentos pro vida son, salvo algunas excepciones, inspirados por posturas religiosas. De allí la pertinencia de traerlas a colación. 
El 14 de noviembre de 2008 envió una carta al presidente de la Asamblea General de la República Oriental del Uruguay planteando sus objeciones al proyecto de ley que establecía normas sobre los derechos sexuales y reproductivos de las mujeres. Vásquez justificó el veto a la legalización del aborto mediante razones cientificas:

La biología ha evolucionado mucho. Descubrimientos revolucionarios, como la fecundación in vitro y el $\mathrm{ADN}$ con la secuenciación del genoma humano, dejan en evidencia que desde el momento de la concepción hay allí una vida humana nueva, un nuevo ser. Tanto es así que en los modernos sistemas jurídicos -incluido el nuestro- el ADN se ha transformado en la "prueba reina" para determinar la identidad de las personas, independientemente de su edad, incluso en hipótesis de devastación, o sea cuando prácticamente ya no queda nada del ser humano, aun luego de mucho tiempo.

\section{Jurídicas:}

La legislación no puede desconocer la realidad de la existencia de vida humana en su etapa de gestación, tal como de manera evidente lo revela la ciencia $[\ldots]$ [Los tratados internacionales] obligan a nuestro país a proteger la vida del ser humano desde su concepción [...] El proyecto, además, califica erróneamente y de manera forzada, contra el sentido común, el aborto como acto médico, desconociendo declaraciones internacionales como las de Helsinki y Tokio [...] y que son reflejo de los principios de la medicina hipocrática que caracterizan al médico por actuar a favor de la vida y de la integridad física.

Culturales: "El aborto es un mal social que hay que evitar", para las mujeres que abortan se debe "buscar una solución basada en la solidaridad". Y razones de conveniencia práctica:

Hay consenso en que el aborto es un mal social que hay que evitar. Sin embargo, en los países en que se ha liberalizado el aborto, es- tos han aumentado. En los Estados Unidos en los primeros diez años se triplicó, y la cifra se mantiene: la costumbre se instaló. Lo mismo sucedió en España (Vásquez, 2012, pp. 9-11).

Las cuatro razones anotadas permiten concluir que Tabaré Vásquez presentó su postura en un estricto lenguaje secular, es decir, traduciendo a un elenco de razones seculares su oposición ética y moral al aborto.

Algo semejante ocurrió con Sebastián Piñera, expresidente chileno, quien intervino en la discusión pública del aborto terapéutico que generó el proyecto de ley que se tramitaba en el Senado en el año 2012. Mediante un artículo publicado en el diario El Mercurio expresó cuatro razones por las cuales era contrario a la despenalización del aborto. Las tres primeras son de orden secular. Jurídicas:

Nuestra Constitución Política asegura a todas las personas el derecho a la vida [...] El niño por nacer (nasciturus) es también una persona, cuya vida debe ser protegida [...] Chile tiene una tradición más que centenaria de protección de derechos fundamentales [...] la forma como una sociedad trata a sus miembros más débiles -los adultos mayores, los enfermos, los más pobres, los que sufren alguna discapacidad y los niños que están por nacer- dice mucho más sobre el grado de su civilización que su riqueza material, o la altura de sus edificios, o la calidad de su infraestructura o su poderío militar.

De conveniencia práctica: "en la duda siempre es mejor optar por la vida". Antropológicas:

No se trata de una decisión que competa solamente a la madre o a los padres del niño que está por nacer. Está involucrada también la vida de un ser nuevo, único, irrepetible y distinto a sus padres, que debe ser defendida con mayor fuerza, precisamente por su condición de plena inocencia e indefensión [...] Los argumentos en favor del aborto eugenésico, que es el que se propugna para situaciones de inviabilidad o malformaciones del feto, y del 
que ha sido denominado aborto ético- social, que permitiría poner término a un embarazo que ha sido consecuencia de una violación, son incorrectos, puesto que supondrían atribuirnos el derecho a clasificar a seres humanos en superiores -aquellos que merecen vivir-e inferiores -aquellos que no merecen vivir-, y, además, condenar a muerte a seres absolutamente indefensos e inocentes de las circunstancias de su concepción.

Mientras que la cuarta y última es de orden religioso -como él mismo reconoce-:

Como cristiano, creo en la vida como un don de Dios. Solo Él tiene el poder para dar la vida y el derecho a quitarla. Por eso, soy partidario de proteger la vida y dignidad humana desde su concepción hasta la muerte natural. Y, por lo mismo, soy también contrario a la eutanasia y la pena de muerte (Piñera, 18 de marzo de 2012).

En el caso de Piñera, la traducción parece obedecer a una convicción y no a una estrategia política de persuasión, pues advierte que es

[...] consciente de que este argumento de naturaleza religiosa, por sí solo, no es suficiente para justificar una prohibición estatal absoluta del aborto en nuestro país. Entre otras razones, porque no tiene sentido debatir en la esfera pública desde convicciones puramente religiosas, que no son susceptibles de ser deliberadas, ni pueden ni deben quedar sujetas a las reglas de mayorías, propias de un sistema democrático (Piñera, 18 de marzo de 2012).

Así mismo, en su discurso aparece el concepto de empatía, que entiende Isaiah Berlin (2010, p. 47) como el esfuerzo por llevar a cabo una penetración psicológica del otro, por tratar de ponerse en sus zapatos, "tratar de entrar en sus ropas", y entender qué es lo que quiere dadas las condiciones en que vive, de acuerdo con su carácter y con su perspectiva, pues Piñera sostiene:

[...] estoy seguro que ninguna madre que recurre al aborto lo hace sin un profundo desgarro interior y, la mayoría de las veces, impulsada por un sentimiento de angustia y abandono. Detrás de esta acción, muchas veces se esconden la desesperación, el desamparo y la incomprensión de la sociedad, y muchas veces también de su familia, lo que la hace sentirse incapaz o imposibilitada de llevar a feliz término su embarazo (Piñera, $18 \mathrm{de}$ marzo de 2012).

La empatía, valga la anotación, es una virtud cívica que cualifica el debate político cuando se enfrentan posturas antagónicas y facilita el compromiso entre los adversarios.

\section{La traducción como forma de argu- mentar en el discurso público.}

El ejercicio discursivo de Vásquez y Piñera en el debate sobre el aborto, y el de Negre de Alonso en la discusión sobre el matrimonio de parejas del mismo sexo de formular sus creencias y valores en términos que puedan ser comprendidos y potencialmente aceptados por todos los ciudadanos, recibe en la teoría política el nombre de deber público de civilidad (Rawls) o de traducción (Habermas). Ambos conceptos pretenden formular una discusión pública en términos de razonabilidad y potencial entendimiento.

¿De qué razonabilidad estamos hablando? Según Rawls, la razonabilidad de las doctrinas comprensivas morales, filosóficas o religiosas está determinada por el cumplimiento del deber de civilidad pública y la contribución de estas doctrinas al equilibrio político en términos de razón pública. De acuerdo con el primero, los ciudadanos,

[...] en cuanto seres razonables y racionales, y sabiendo que profesan una diversidad de doctrinas razonables, religiosas y filosóficas, deberían ser capaces de explicarse unos a otros los fundamentos de sus actos en términos que cada cual espere razonablemente que los demás puedan suscribir, por ser congruentes con su libertad y su igualdad ante la ley (Rawls, 2006, p. 208). 
Conforme con el segundo parámetro, las doctrinas comprensivas deben apoyar el consenso entrecruzado del liberalismo político. Es decir, las doctrinas comprensivas prueban su razonabilidad al apoyar la concepción política de la justicia y de los elementos constitucionales esenciales, lo cual se traduce principalmente en iguales derechos y libertades de carácter básico para todos los ciudadanos.

El deber de civilidad pública tiene una coincidencia esencial con la traducción. Esta categoría se inserta en un contexto postsecular y posmetafísico en el que la religión ya no tiene el monopolio interpretativo y de estructuración de la existencia (Habermas, 2008, p. 30). Por ello, los creyentes deben formular sus creencias religiosas en un lenguaje secular, lo cual las legitima cuando comparecen en el sistema político - es el caso de la carta que Vásquez como titular del poder ejecutivo le remite al presidente del órgano legislativo-, y les otorga el potencial de ser comprendidas y eventualmente compartidas por quienes tienen una base epistémica y axiológica diferente.

Cuando pretenden ser acogidas en ámbitos del sistema político, la traducción de las creencias religiosas a un lenguaje secular es una exigencia originada en la separación entre las iglesias y el Estado. Este diseño institucional exige que entre estas dos esferas haya un filtro encargado de dejar pasar únicamente las aportaciones "traducidas" en términos seculares procedentes de toda la babel de voces del ámbito público y las traslade hasta las agendas de las instituciones estatales (Habermas, 2009a, p. 79). De este modo, en los discursos prácticos que comparecen en la deliberación democrática cuentan aquellos intereses que se presentan como valores reconocidos intersubjetivamente y son candidatos a ser admitidos en el contenido semántico de normas válidas (Habermas \& Rawls, 1998, p. 155).

Epistemológicamente, la justificación de la traducción está en la primacía del lenguaje secular en una sociedad posmetafísica. Políticamente, porque legitima la democracia (Lafont, 2007 , p. 240) y constituye una forma eficaz de presentar al público el discurso religioso en una sociedad postsecular. Así lo resume Elena Beltrán (2008):

En una sociedad democrática liberal y no homogénea en cuanto a creencias es razonable pensar que aquellos que pretenden seguir los dictados de su religión y defienden la existencia de leyes o regulaciones restrictivas con las conductas humanas que desean que afecten a todas las personas, creyentes o no, han de hacerlo ofreciendo razones no religiosas para apoyar la medida en cuestión. Han de ofrecer razones no fundamentadas en sus creencias exclusivamente, en el sentido de que no han de ser razones cuya fuerza normativa y justificatoria se derive de la existencia de Dios o de razones teológicas o de los dictámenes de autoridades religiosas. Esto quiere decir que si bien el argumento puede estar inspirado de algún modo en la religión, ha de poder ser traducido en términos aceptables por los no religiosos, también se pueden utilizar argumentos religiosos para clarificar posiciones, pero el argumento principal ha de ser laico (p. 51).

Ala justificación epistemológica y política se añaden unas consideraciones simbólicas y discursivas que consisten en que

[...] en el discurso religioso se mantiene un potencial de significado que resulta imprescindible y que todavía no ha sido explotado por la filosofía y, es más, todavía no ha sido traducido al lenguaje de las razones públicas, esto es, de las razones presuntamente convincentes para todos (Habermas, 2001, p. 201).

Luego, la expresión racional en términos seculares modernos de la gramática religiosa es un proceso inacabado que tendrá un resultado difícil de prever (Habermas, 2001, p. 103) y al cual desde la praxis política contribuyeron dirigentes como Negre de Alonso, Vásquez y Piñera, debido al lugar privilegiado que sus voces ocuparon en el debate público. 
El deber de civilidad pública, la traducción y la teoría de la ley natural -con la cual tienen notorias coincidencias (Garzón Vallejo, 2013)no son exclusivamente un ejercicio intelectual. Expresan un talante político liberal y republicano en un contexto cultural postsecular. Ello no significa, sin embargo, que la apropiación de un lenguaje secular por parte de las tradiciones religiosas sea un proceso originado en la modernidad. Ciertamente, la dialéctica entre la racionalidad secular y la racionalidad religiosa, marcada por el aprendizaje, la apropiación crítica y la elaboración de nuevas categorías filosóficas hunde sus raíces en la antigüedad y atraviesa el medioevo (Habermas, 2001, p. 185; 2009b, p. 237). No obstante, como es patente en los casos de Feliciano, Zavala, Gerlein y Murillo, es una asignatura pendiente en contextos políticos tradicionalistas o en los cuales hay un uso instrumental del discurso religioso en forma de legitimación partidista.

El deber de civilidad pública y la traducción, por su parte, no consisten en una forma de ocultar estratégicamente las creencias religiosas con un ropaje de laicidad. Por ello es importante identificar los usos meramente estratégicos o electorales, los cuales, al minar la credibilidad de las razones públicas, se convierten en parasitarios de la deliberación democrática ${ }^{5}$. Asílas cosas, en el uso del lenguaje secular es preciso indagar si un líder político tiene la convicción de que este contribuye a una deliberación democrática más razonable y a una mejor ciudadanía. Y en el recurso a referencias religiosas se debe examinar si estas contribuyen a ampliar los márgenes de la discusión, o solo son funcionales a obtener un beneficio electoral del mismo.

No es momento de identificar las contradicciones y ambivalencias del deber de civilidad pública y la traducción (Garzón Vallejo, 2010; Lafont, 2007), sino de resaltar que se trata de una propuesta para sociedades liberales y postseculares cuya pretensión es dotar de razonabilidad las posturas morales y religiosas que intervienen en la deliberación de asuntos públicos en el sistema político y en la esfera pública política, y que constituyen una forma de modernización del discurso político.

\section{Conclusiones}

Al revisar los siete casos analizados, una conclusión evidente a la que arribamos es que el discurso público de los políticos latinoamericanos parece oscilar entre el uso de un lenguaje religioso explícito y la traducción. Pero también, el desarrollo que tuvo uno de los casos en estudio -el de Nelson Zavala- permite llegar a otra conclusión, y es que el debate entre religión y política en América Latina suele oscilar entre los extremos del tradicionalismo y el laicismo.

El discurso de Nelson Zavala puede ser calificado como tradicionalista porque en la discusión de cuestiones públicas controversiales (como es el caso de los derechos de las parejas homosexuales), no recurrió a un uso discursivo que pudiera ser comprensible por quienes no comparten su cosmovisión religiosa, y por el contrario, fundó su posición en una interpretación literal de un texto sagrado del cual desprende consecuencias normativas que espera aplicar incluso a quienes no comparten la creencia de que la Biblia tenga un alcance político.

Pero entre tanto, el Tribunal Contencioso Electoral lo sancionó por lo que consideró un comportamiento discriminatorio contra la comunidad homosexual y advirtió que una resolución del Consejo Nacional Electoral (CNE) no solo prohibía las expresiones discriminatorias sino las "alusiones de carácter religioso" (Causa No. 148-2013-TCE de 2013). Es decir, el CNE ecuatoriano decidió que las organizaciones políticas deben renunciar a las expresiones religiosas, deben "actuar con independencia de ministros de culto de cualquier religión", y no podrán usar "ningún elemento que aproveche indebidamente la fe religiosa" (Consejo Nacional Electoral del Ecuador, 2014). 
Tales disposiciones son un ejemplo de laicismo, porque no permiten que sea la propia dinámica de la deliberación democrática la que pondere o deseche el valor de los argumentos religiosos, y porque la exclusión de las creencias y razones religiosas en la contienda electoral vulnera las libertades constitucionales de religión, culto, conciencia y expresión. Pero sobre todo, constituye un error de los laicistas -atrincherados en decisiones como esta- creer que los creyentes dejarán su religión en la puerta antes de ingresar al ámbito público (Obama, 28 de junio de 2006). Ello explica que a pesar de la separación formal y constitucional existente en los Estados latinoamericanos, algunas leyes y políticas públicas están condicionadas por el peso de los poderes religiosos y eclesiásticos (Blancarte, 2013, p. 19).

Por último, aunque a partir de los casos estudiados es posible identificar en algunos políticos latinoamericanos $\mathrm{su}$ compromiso y convicción con una forma de expresión moderna del discurso político-Tabaré Vásquez, Sebastián Piñera y Liliana Negre de Alonsoen su inspiración ideológica y en su gramática pública, al mismo tiempo, se observaron mayoritariamente discursos políticos cuya perspectiva religiosa y moral es refractaria a asumir las pautas discursivas y deliberativas de una democracia postsecular -Marco Feliciano, Nelson Zavala, Roberto Gerlein y Rosario Murillo-, tanto en el sistema político (intervenciones en los órganos legislativos) comoen la esfera pública política (intervenciones en los medios de comunicación). En este elenco de políticos también se comprobó una negativa radical a utilizar el lenguaje religioso de forma que pueda ayudar a construir un terreno común sobre el cual puedan discutir y discrepar todos los ciudadanos.

La búsqueda de este terreno común cultivado por la razonabilidad y la empatía en el que sea posible el entendimiento de todos los ciudadanos constituye el mejor propósito al cual deberían contribuir los políticos latinoamerica- nos, bien sea con razones seculares o con razones religiosas. Y los ciudadanos harían bien en exigírselo.

\section{Notas}

1 Argentina (2010), Colombia (2012 y 2015), Uruguay (2013), Chile (2012), Perú (2013), México (2013), Venezuela (2014), Costa Rica (2013 y 2015) y Bolivia (2012).

2 Chile (2013 y 2014), Uruguay (2011), Argentina (2010), Ecuador (2013), Colombia (2011), Bolivia (2013), Perú (2013 y 2014), Costa Rica (2013) y México (2013).

3 "La unión homosexual no es normal. El recto no fue hecho para ser penetrado. No habría forma de dar continuación a nuestra raza. Ahora, lo que se hace dentro de las cuatro paredes no me concierne $[. .$.$] Los gais destruyen$ a cualquier persona que se levante contra ellos. El matrimonio gay viola los derechos de la iglesia" (traducción libre).

4 "Una casa dividida contra sí misma no se mantiene en pie. Creo que este Gobierno no puede perdurar medio esclavo y medio libre. No espero que la Unión se disuelva -no espero que la casa se caiga-, sino que espero que deje de estar dividida" (Lincoln, 2005, p. 143).

5 En la campaña presidencial de 2010 en Colombia, un periodista del diario español $E l$ Mundo le preguntó al candidato Juan Manuel Santos: "¿Qué tiene Santos que no tiene Mockus?", a lo que este respondió: "Yo creo en Dios" (Argüello, 29 de abril de 2010).

\section{Referencias}

Argüello, F. (29 de abril de 2010). Juan Manuel Santos: 'Tengo lo que no tiene Mockus: Creo en Dios'. Elmundo.es. Recuperado de http:// www.elmundo.es/america/2010/04/29/colombia/1272507133.html 
Beltrán, E. (2008). Sobre dioses, derechos y leyes: la igualdad en el uso público de la razón. Revista Internacional de Filosofía Política, 32, 47-62.

Berlin, I. (2010). El fin del ideal de la sociedad perfecta. En J. Giraldo Ramírez (Ed.), Isaiah Berlin: utopía, tragedia y pluralismo. Medellín: Fondo Editorial Universidad EAFIT.

Blancarte, R. (2013). Laicidad en México. México: Universidad Nacional Autónoma de México; Cátedra Extraordinaria Benito Juárez; Instituto de Investigaciones Jurídicas; Instituto Iberoamericano de Derecho Constitucional.

Bohoslavski, E. (2013). Laicidad y América Latina. México: Universidad Nacional Autónoma de México; Cátedra Extraordinaria Benito Juárez; Instituto de Investigaciones Jurídicas; Instituto Iberoamericano de Derecho Constitucional.

Derrida, J. (2006). El siglo y el perdón/Fe y saber (2a ed., Trad. M. Segoviano, C. De Peretti \& P. Vidarte). Buenos Aires: Ediciones de la Flor.

Feliciano, M. (2013). Eu acredito no diálogo. Veja, 2313. Recuperado de http://www. desktopgospel.com.br/2013/03/marcofeliciano-nas-paginas-amarelas-da.html

Funes, M. (2010). Discurso en el XVIII aniversario de la firma de los Acuerdos de Paz. Diario Digital ContraPunto. Recuperado de http://www.josesaramago. org/discurso-de-mauricio-funes-en-elaniversario-de-los-acuerdos-de-paz/

Garzón Vallejo, I. (2010). Los dilemas del carácter público de los argumentos filosóficos y religiosos en el liberalismo de John Rawls. Praxis Filosófica, 30, 39-64.
Garzón Vallejo, I. (2013). Public Reason, Secularism and Natural Law. En F. J. Contreras (Ed.), The Threads of Natural Law. Unravelling a Philosophical Tradition (pp. 223-242), Londres: Springer Netherlands.

Garzón Vallejo, I. (2014). La religión en la razón pública. Buenos Aires: Editorial Astrea; Universidad de La Sabana.

Gerlein, R. (2012). Senador Roberto Gerlein declara en contra de los homosexuales. Recuperado de http://www.youtube.com/ watch $? \mathrm{v}=\mathrm{NhWIooLt} 4 \mathrm{io} \# \mathrm{t}=0$

Habermas, J.(1990). Pensamiento postmetafisico (Trad. M. Jiménez-Redondo). Madrid: Taurus.

Habermas, J. (2001). Israel o Atenas. Ensayos sobre religión, teología y racionalidad. (Trad. de Manuel Jiménez Redondo). Madrid: Editorial Trotta.

Habermas, J. (2002). El futuro de la naturaleza humana. ¿Hacia una eugenesia liberal (Trad. R. S. Carbó). Barcelona: Paidós.

Habermas, J. (2006). Religion in public sphere. European Journal of Philosophy, 14(1), 1-25.

Habermas, J. (2008). ¿Fundamentos prepolíticos del Estado democrático de Derecho? (Trad. I. Blanco \& P. Largo). En J. Habermas \& J. Ratzinger (Eds.), Entre razón y religión. Dialéctica de la secularización (pp. 9-34). México: Fondo de Cultura Económica.

Habermas, J. (2009a). ¡Ay Europa! Pequeños escritos políticos (Trad. P. Madrigal \& F. J. Gil). Madrid: Editorial Trotta.

Habermas, J. (2009b). El Occidente escindido (2a ed., Trad. J. L. López). Madrid: Editorial Trotta. 
Habermas, J., \& Rawls, J. (1998). Debate sobre el liberalismo político (Trad. G. VilarRoca). Barcelona: Paidós.

Lafont, C. (2007). Religion in the Public Sphere: Remarks on Habermas's Conception of Public Deliberation in Postsecular Societies. Constellations, 14(2), 239-259.

Lincoln, A. (2005). El Discurso de Gettysburg y otros escritos sobre la Unión (Trad. J. Alcoriza \& A. Lastra). Madrid: Tecnos.

Losada, R., \& Casas, A. (2008). Enfoques para el análisis político. Historia, epistemología $y$ perspectivas de la ciencia política. Bogotá: Editorial Pontificia Universidad Javeriana.

Marshall, W. P. (2002). The Limits of Secularism: Public Religious Expression in Moments of National Crisis and Tragedy. Notre Dame Law Review, 78(1), 11-33.

Murillo, R. (2008). La conexión "feminista" y las guerras de baja intensidad. Presidencia de la República de Nica-ragua. http://www. presidencia.gob.ni/index.php?option $=\mathrm{com}$ content $\&$ view $=$ article $\&$ id $=157 \% 3$ Alaconexion-feminista-y-las-guerras-debaja-intensidad- $\&$ catid $=52 \% 3$ Aagosto2008\&Itemid $=1$

Obama, B. (28 de junio de 2006). Obama's Speech on FaithandPolitics.New YorkTimes. Recuperado de http://www.nytimes.com/2006/06/28/ us/politics/2006obamaspeech.html?page wanted $=$ al

Ortega, D. (2012). Homenaje al General Augusto C. Sandino. Presidencia de la República de Nicaragua. Recuperado de http://www.presidencia.gob.ni/ indexphp?option=com_content\&view $=$ article $\& \mathrm{id}=410$ :homenaje-al-generalaugusto-c-sandino\&catid $=96$ : mayo2012\&Itemid $=54 \&$ showall $=1>$
Ortega, D. (2013). Daniel y Rosario en Homenaje a Sandino en su 118 Natalicio. Presidencia de la República de Nicaragua. Recuperado de http://www.presidencia.gob.ni/index. php?option=com_content\&view=article\&id= 446:daniel-y-rosario-en-homenaje-a-sandinoen-su-118-natalicio\&catid=102: mayo2013\&Itemid $=54$

Pew Research Center. (2014). Religion in Latin America. Widespread change in a Historically Catholic Region. Recuperado de http://www.pewforum.org/files/2014/11/ Religion-in-Latin-America-11-12-PM-fullPDF.pdf

Piñera, S. (18 de marzo de 2012). Mi compromiso con la vida. El Mercurio. Recuperado de http://impresa.elmer curio.com/pages/LUNHomepage.aspx? BodyID $=1 \& \mathrm{dt}=2012-03-18 \& \mathrm{dtB}=2012-$ 03-18\&dtB=18-03-2012

Rawls, J. (2006). Liberalismo político (Trad. S. R. Madero). México: Fondo de Cultura Económica.

República Argentina. Negre de Alonso, L. (2010). Versión taquigráfica (provisional). Cámara de Senadores de la Nación. $14^{\circ}$ Reunión, $9^{\circ}$ sesión ordinaria, 14 y 15 de julio. Recuperado de http://www.senado. gov.ar:88/9078.pdf

República del Ecuador. Causa No. 148-2013TCE (Acumulada 165-2013-TCE) (2013, marzo 11). Despacho del Dr. Patricio Baca Mancheno. Tribunal Contencioso Electoral del Ecuador. Recuperado de http://www. tce.gob.ec/jml/bajar/Sentencias/04eb7d_

SENTENCIA-148-13-110313.pdf

República del Ecuador. Consejo Nacional Electoral del Ecuador. (2014). Guía No. 1 Conocimientos generales para la participación de las organizaciones politicas en el proceso electoral 2014. Re- 
cuperado de http://institutocne.gob.ec/ publicaciones/317-guia-no-1-conocimientos-generales-para-la-participacionde-las-organizaciones-politicas-en-elproceso-electoral-2014

Rojas, C. (2012). La persistencia del lenguaje religioso en el discurso político. El caso de Hugo Chávez. Revista Civilizar Ciencias Sociales y Humanas, 13(24), 157-164.

Salinas, C. (2 de noviembre de 2011). Daniel Ortega utiliza el embarazo de una niña en su campaña de reelección. El País. Recuperado de http://internacional. elpais.com/internacional/2011/11/02/ actualidad/1320251317_399319.html

Taylor, C. (2011). Por qué necesitamos una redefinición radical del secularismo (Trad. J. M. Carabante \& R. Serrano). En. J. Habermas, C. Taylor, J. Butler \& C. West (Eds.), El poder de la religión en la esfera pública (pp. 39-60). Madrid: Editorial Trotta.
Van Antwerpen, J. (2008). Reconciliation reconceived: Religion, secularism, and the language of transition. En K, Will (Ed.), The politics of reconciliation in multicultural societies (pp. 25-47). Oxford: Oxford University Press.

Vásquez, T. (2012). Las 15 tesis presentes en el veto de Tabaré Vásquez. En L. Van Rompaey et al. (Eds.), Veto al aborto. Estudios interdisciplinarios sobre las 15 tesis del Presidente Tabaré Vásquez (pp. 9-11). Montevideo: Universidad de Montevideo.

Zavala, N. (23 de noviembre de 2012). Candidato presidencial Nelson Zavala: "La homosexualidad es un acto de inmoralidad". Recuperado de http://ecuadorinmediato.com/ index.php?module $=$ Noticias $\&$ func $=$ news user view\&id $=186074 \&$ umt $=$ candidato presidencial nelson zavala la homosexualidad_es_un_acto_inmoralidad_audio 